\title{
AINDA SOBRE O CETICISMO SEMÂNTICO
}

André Klaudat

SINTESE - 0 ceticismo semântico é uma posição filosófica que nega que regras, por si mesmas, podem determinar o que deve ser feito. A solução para o problema de explicar como afinal é possível a existência do significado lingüístico é dada através de comunidades de falantes. Kripke defende esta visão das coisas, especialmente com relação às reflexōes de Wittgenstein sobre o assunto. Eu argumento, em primeiro lugar, que o cetícismo semântico é uma posiçăo equivocada por não entender bem um ponto central do problema, que foi esclarecido por Wittgenstein: regras e aplicaçōes corretas das mesmas estão relacionadas internamente. Entender bem isso requer, no entanto, clareza sobre o que é uma regra. Contra Malcolm procuro mostrar, num segundo momento, a importância que tern em Wittgenstein a concepção dinâmica das regras: só será uma regra e uma formulação da mesma o que funcionar como guia, como padrão, como critério, num conjunto de práticas e técnicas. Conceber regras desta maneira permite que se compreenda o que é ver a linguagem de uma maneira normativista. Ao final, procuro esclarecer melhor como as regras têm força normativa dentro de práticas e técnicas que supōem, sem embargo, condições de normalidade. Argumento, contudo, que estas condiçōes não são 0 que dá força às regras tout court.
ABSTRACT - Semantic Scepticism is a philosophical position which denies that rules by themselves can determine what ought to be done. The solution to the problem of explaining how the existence of linguistic meaning is possible is given through communities of speakers. Kripke holds such a view of things, particularly in connection with the import of Wittgenstein's reflections on the matter. I argue, in the first place, that Semantic Scepticism is illconceived, because it does not account for a central element of the problem, which has been elucidated by Wittgenstein: rules and their correct application are internally related. To appreciate this it requires, however, understanding what a rule is. Contra Malcom I try to show, in the second place, what role the dynamic conception of rules plays in Wittgenstein: it will be a rule only and a formulation of one what functions as a guide, as a standard, as a criterion, in practices and techniques. Such a conception of rules allows one to grasp what it means to see language in a normativist way. At the end, I attempt to clarify further how rules have normative power within practices and techniques which, none the less, take for granted conditions of normalcy. I argue, however, that these conditions are not what gives power to rules simpliciter.

\section{1 - Introdução: o que é o ceticismo semântico}

Ceticismo semântico é o nome de uma concepção filosófica. Ela caracterizase por perguntar "como é possivel que uma regra determine um caso de sua aplicação?", e por responder ou sugerir a resposta "não é possível que uma regra faça isto". Por isso, ela também é conhecida como ceticismo de regras. Alguém pode 
se convencer de que há um problema filosófico que diz respeito à noção de seguir regras refletindo sobre o assunto de uma ou mais das seguintes maneiras: (1) como é possível que alguém que aprendeu uma regra aplique a mesma um número ilimitado de vezes? Imagina uma pessoa que aprendeu a regra sintática de que toda oração tem que ter sujeito e predicado. Como é possível que toda a tentativa futura por parte desta pessoa de formar uma oração seja determinada por esta regra? Imagina toda a gama de termos que podem ser o sujeito de uma oração, e toda a gama de verbos e predicativos, dos quais a pessoa não tinha nenhuma noção quando aprendeu a regra. Como pode que todos os novos casos de formação de uma oração sejam determinados pela regra que provavelmente foi apresentada à pessoa através da formulação "toda oração tem que ter sujeito e predicado" e eventualmente por alguns exemplos? (2) supõe uma ação que parece ser determinada por uma regra. Esta determinação é, na verdade, somente aparente, pois é sempre possível que esta ação seja determinada ou exigida por uma outra regra ou por uma interpretação "divergente" da regra. Desta maneira nenhuma ação é de fato, apesar das aparências em contrário, determinada por uma regra. Imagina alguém que entra na igreja e, antes de se ajoelhar para rezar, faz o sinal da cruz. Perguntado por que, responde que tinha aprendido de sua avó que tocar estas quatro partes do corpo antes de rezar o punha em contato íntimo com todo o universo, pois os pontos representam os pontos cardeais [sic]. Pode-se ainda imaginar alguém que sabe que este sinal é o sinal da cruz, mas que no entanto se explica dizendo "estou indicando a Deus por onde a energia divina que vai me redimir deve entrar em mim" [sic]. Estes são casos de um mesmo comportamento: mas não de uma mesma ação, porque não são casos de estar-se seguindo uma mesma regra; (3) nesta mesma linha, é sabido que qualquer seqüência finita de números é compatível com um número infinito de séries matemáticas. Ou seja, um dado conjunto de casos supostamente determinados por uma regra pode ter sido determinado na verdade por uma outra regra de um conjunto infinito de regras. Desta forma parece seguir-se que uma regra não pode determinar suficientemente um caso de sua aplicação. Outras coisas têm que estar envolvidas também. Portanto, como regras determinam casos de sua aplicação não é algo filosoficamente cristalino.

O ceticismo semântico apareceu no cenário filosófico contemporâneo com a interpretação das reflexões do "segundo" Wittgenstein sobre o conceito de seguir regras. Saul Kripke ofereceu a sua interpretação do que Wittgenstein pretendia com estas reflexões, especialmente nas Investigações Filosóficas: mostrar a força do ceticismo semântico e oferecer-lhe uma resposta cética ${ }^{1}$. $O$ cerne desta interpretação pode ser exposto da seguinte maneira, e eu utilizarei os elementos e termos da reflexão do próprio Wittgenstein nesta exposição ${ }^{2}$.

Cf. Kripke, Saul, Wittgenstein on Rules and Private Language (Blackwell, Oxford, 1989).

2 Cf. Wittgenstein, Philosophical Investigations (Blackwell, Oxford, 1989; tradução de G.E.M. Anscombe), \#185 e seguintes. A tradução para o português de passagens desta obra, que será citada através de "PP" e número do parágrafo (parte 1) ou página (parte 2), e de outras obras em inglês é minha. 
Não há como seguir ou até mesmo infringir uma regra objetivamente, pois, como as reflexões de (1) a (3) acima procuraram deixar claro, na formulação de Wittgenstein mesmo, "nenhum modo de agir poderia ser determinado por uma regra, porque todo modo de agir pode ser levado a concordar com a regra" (PI \#201). Wittgenstein joga aqui com a implicação do que foi considerado principalmente nas reflexões (2) e (3): se a regra não determina nenhum modo de agir, então todo modo de agir pode ser tomado de uma maneira tal que acabe concordando com a regra. Para Kripke este é o problema central das PI, este que é no seu entender um "paradoxo cético". Portanto, não há nem conformidade nem contradição com a regra, considerada a situação desta maneira.

Conseqüentemente, 0 aluno que no parágrafo 185 das $P I$ é mandado seguir a série dos números após 1000 usando a regra “+2" não sabe realmente como seguir a instrução, pois caso contrário ele deveria estar se fiando somente na regra, o que pelas razões aduzidas anteriormente não parece ser suficiente. Mas esta situação é por demais contra-intuitiva. Além disto, levada adiante com rigor implicaria que nem mesmo quem ordena "forma a série de números que começa em 1000 usando '+2'" sabe o que está ordenando, pois nem ele poderia se fiar na regra “+2". Se esta situação extrema fosse alcançada não haveria mais significado lingüístico de qualquer espécie, por isso o termo ceticismo semântico. É aqui que entra em cena a "resposta cética": o que torna a série formada pelo aluno - "1000, 1002, 1004, 1006,..." - correta é a aceitação da mesma como tal pela comunidade lingüística da qual o aluno faz parte. É também esta comunidade que afinal determina que a série "1000, 1004, 1008, 1012,..." é incorreta. É em função do papel que a comunidade (a comunidade lingüística, que decide o que chamamos de correto ou incorreto) desempenha neste problema que alguns interpretes (inclusive Kripke) pensam que Wittgenstein defende um "ponto de vista da comunidade" ou comunitarismo. O aluno, então, se fiaria na comunidade, no que ela diz e obviamente faz, e não exclusivamente na regra.

Estes pontos, esta discussão em torno do ceticismo semântico de Wittgenstein é considerada parte de um debate ainda inacabado ${ }^{3}$. Eu não concordo com isto, obviamente não no sentido de achar que o debate não acontece mais. Sendo assim, o propósito do meu artigo é chamar a atenção para um elemento crucial na posição de Wittgenstein sobre seguir regras, elemento este que é constantemente ignorado ou mal-entendido pelos proponentes do ceticismo semântico ou até mesmo por estes que pensam que há no "segundo" Wittgenstein "uma atitude cética de ordem prático-normativa". Este elemento é o ponto conceitual de que a relação entre uma regra e uma aplicação correta da mesma é uma relação intema. Entender isto adequadamente tem como conseqüência o reconhecimento de que 0 ceticismo semântico é insustentável. O rationale deste elemento é algo que se faz sentir em muitas das reflexões de Wittgenstein: a visão normativista da lingua-

3 Cf. Nythamar F. de Oliveira, "Significado e Skepsis nas 'Investigaçöes' de Wittgenstein" (Veritas, Porto Alegre, mar. 1996), p. 67.

4 Op. cit., p. 72.0 apelo do "segundo" Wittgenstein à noção de uso e sua vontade de argumentar contra a "lógica da subjetividade" seriam evidências de que Wittgenstein estaria apresentando formas de vida, práticas e regularidades como elementos "que permitem ao cético manter o significado da existência de objetos físicos sem contra-senso" (p. 74, sic). 
gem. Atividades lingüísticas são normativas ou governadas por regras. O ceticismo semântico e o "ponto de vista da comunidade" ou comunitarismo sobre seguir regras - emenda que é pior que o soneto - não conseguem vislumbrar quais são as implicações que têm de reconhecer que a linguagem é uma atividade guiada por regras, quando estas são devidamente compreendidas.

A minha discussão se centrará no conceito de regra. É importante esclarecer o que são regras e como se pode conceber que regras determinam o que está de acordo com elas. A discussão dirá respeito, num primeiro momento, ao cético tipo kripkeano (seção 2). Na sequêência (seção 3) a posição - embora não cética, antes inesperadamente comunitarista - de Norman Malcolm será analisada. Argumentarei que também Malcolm não compreendeu o que é fundamental sobre regras. Nesta linha, a investigação abordará, por fim (seção 4), o que está à base dos fenômenos normativos: a "armação". Compreender isto adequadamente permitirá conceber como regras, elas mesmo, determinam o que é correto. $O$ presente exercício de argumentação pretende não só apresentar Wittgenstein corretamente, mas também fazer sentido filosoficamente.

\section{2 - A "resposta cética", seus erros e as relações internas}

Saul Kripke acredita que o "paradoxo cético" que ele encontra no parágrafo 201 das PI tem a sua solução enunciada no parágrafo 202:

\footnotetext{
“E por isso também 'seguir uma regra' é uma prática. E acreditar que se está seguindo a regra não é seguir a regra. Por isso não é possivel seguir uma regra 'privadamente': senão, acreditar que se está seguindo uma regra seria a mesma coisa que seguir uma regra."
}

$\mathrm{Na}$ leitura de Kripke deste parágrafo o que Wittgenstein estaria propondo seria o "ponto de vista da comunidade". A prática a que se refere o texto seria a prática de uma comunidade, e o acreditar que se está seguindo a regra seria o que todos nós necessariamente fazemos ao pretender seguir uma regra, mas que não garante que de fato se esteja seguindo a regra. $O$ ponto central do argumento de Kripke é, conseqüentemente, o seguinte: dado que acreditar que se está seguindo uma regra não é certamente segui-la, não se pode seguir uma regra privadamente, isto é, um indivíduo não pode saber se está seguindo uma regra ou não; e a única solução para o problema é reconhecer que a comunidade na qual o indivíduo se insere é que assegura a aplicação correta da regra. A evidência mais forte para esta leitura de Wittgenstein estaria no parágrafo 199 das PI, onde Wittgenstein estaria afirmando que não é possível para uma pessoa sozinha seguir - e em uma única ocasião - uma regra. A pergunta que eu quero fazer agora é a seguinte: como pode uma prática cumprir este papel, e uma prática concebida como comunitária?

Vamos ver primeiramente a motivação por trás da "solução cética". Pensemos no caso de somar 2. Suponhamos que ao aluno ao qual já fiz referência é ordenado somar 2 a partir de zero, completando a série " $0,2,4,6,8, \ldots$ ”. Depois de 1000, no entanto, o aluno escreve " $1004,1008,1012, \ldots$... Se o víssemos escrevendo " 582 , $584,586, \ldots$, pensaríamos que ele entendeu a regra. Mas, quando somos surpre- 
endidos com aquela série após 1000 pensamos "erradol". Bem, coloquemo-nos no lugar do aluno. Ele recebeu a ordem "Forma uma série de números somando $2 \mathrm{e}$ começando por 0 : a série será ' $0,2,4,6,8, \ldots$,'”. O aluno começou então a escrever a série e tendo chegado a 1000 escreveu "1004, 1008, 1012,...". É claro que do ponto de vista do aluno ele ainda está formando a série de acordo com a ordem recebida. Mas pode ele saber o que é uma aplicação correta da regra de somar 2 até mesmo quando escreve " $582,584,586, \ldots$..? Como poderia ele saber se o passo “1000, 1004,..." é correto? No que pode ele se fiar?

A ordem que 0 aluno recebeu contém uma formulação da regra nos seguintes termos aproximados "soma 2". Além disto, foi-lhe apresentado o início da série de números, ou seja, o resultado das primeiras aplicações da regra, que funcionam como um padrão. Pode ele tirar desta formulação da regra e até mesmo do padrão apresentado alguma indicação de que o passo “1000, 1004,..." é incorreto? Parece claro que não. Pensa nas dificuldades que têm os alunos do primário escolar quando thes são dadas ordens parecidas. Poderia o aluno se fiar na sua prática de somar 2 até 1000 ? Também é claro que não, pois é precisamente esta que é compatível com a seqüência " $1000,1004,1008,1012, \ldots$ " aos olhos do aluno. 0 ceticismo semântico recusa esta opção por entender que esta prática, a do aluno, que é privada, não pode cobrir a lacuna que há entre o que foi oferecido ao aluno e 0 passo a respeito do qual se põe a questão "é certo ou errado?" Basicamente, porque esta prática é por princípio compatível com seguir a regra erroneamente deste ponto em diante. Eis por que a prática que pode oferecer a solução buscada pelo ceticismo semântico tem que ser a prática de uma comunidade. Em última instância é a comunidade que, em função da prática comunitária de somar 2, julgará que a série obtida pelo aluno depois de 1000 é uma série obtida através da aplicação incorreta da regra de somar 2.

Uma primeira objeção a esta "resposta cética" é a seguinte. Se o aluno não puder saber o que é a aplicação correta de "+2" a partir da enunciação da regra, como poderá ele saber o que fazer se alguém da comunidade lhe disser: "Está certo, continua assim" ou "Vê o que tu fizeste, pára aí mesmo" (cf. PI, \#185). Este ponto na verdade indica que a "resposta cética" deixa muito a desejar como resposta. Mas isto é muito rápido.

Uma objeção que vai mais fundo, principalmente por deixar mais claro onde quem segue o ceticismo semântico se desencaminha, é a seguinte. Ela gira em torno do que significa correção em relação às regras. Entender uma regra é saber aplicá-la, isto é, saber o que concorda com ela e o que dela discorda. Isto porque regras são padrões de correção. Regras em geral não descrevem, por exemplo, como pessoas falam, elas ao invés definem o que é falar corretamente ou significativamente ${ }^{5}$. Portanto, o que confere correção ao passo "1000, 1002,..." na formação da série dos números a partir da regra de somar 2 não é o fato de que a comunidade, na qual se insere o indivíduo que está formando a série, chama este passo "certo". Ao contrário, o que torna um passo certo ou correto é ele estar de fato de acordo com a regra. "Certo", "correto", é o que está conforme à regra, e não o que está conforme ao que uma comunidade de pessoas julga estar certo ou

- Cf. Glock, H. J., A Wittgenstein Dictionary (Blackwell, Oxford, 1996), p. 324. 
correto. Ou seja, "aplicar a regra corretamente" não significa o mesmo que "aquilo que a maioria das pessoas fazem". Aplicar a regra corretamente significa segui-la de fato.

“' $25^{2}=625$ ' não pode ser a proposiçăo empírica de que pessoas calculam desta maneira, porque neste caso $25^{2} \neq 626$ năo seria a proposição de que pessoas não obtêm este mas outro resultado; e ela poderia também ser verdadeira se as pessoas não calculassem" ${ }^{\text {"t }}$.

No entanto, como isto dá conta da lacuna que há entre o que é oferecido ao aluno e o que ele faz no enésimo passo de aplicação da regra? Como funcionam regras que são padrões de correção? Ou melhor ainda, como regras chegam a ser estes pađrões? O que a objeção acima concernente ao sentido de "correto" combate é justamente a idéia de que existe a referida lacuna. Insistir que a regra é um padrão de correção é ressaltar que a relação que há entre a regra e a aplicação correta da mesma é uma "relação interna". Mas então uma pergunta que é chave se impõe com toda força: como é que o aluno pode saber o que a ordem de formar a série de números somando 2 significa? $\mathrm{E}$ aqui cabe explicar no que importa afirmar que a relação entre a regra e sua aplicação correta é "interna". Isto nos levará a compreender o que uma regra é e como ela determina o que deve ser feito.

A resposta à pergunta que é chave só pode ser: através de nossas explicações. Portanto, o aluno pode saber que depois de 1000 a série deve continuar com "1002, 1004, 1006, 1008,...", pois se a ordem "forma a série de números começando em zero somando 2" exigisse que 0 aluno somasse 2 até 1000 e depois passasse a escrever "1004, 1008, 1012,...", então esta ordem não seria formulada usandose "Soma 2", nem seria ela exemplificada usando-se "0, 2, 4, 6, 8,...". O ponto é 0 seguinte. Dadas as nossas técnicas de aritmética há um ônus por parte de quem ordena, caso ele queira que a série mude depois de 1000, um ônus de dizer algo como "soma 2 até 1000 , depois 4". Ou seja, dada a regra oferecida ao aluno para formar uma série de números (começar com zero e somar 2) o passo correto após 1000 é "1002,..."; caso contrário não diríamos entre outras coisas que a série a ser formada é a dos números pares, que ela começa com " $0,2,4,6,8, \ldots$,. etc. ${ }^{8}$ Portanto, a relação entre a regra e sua aplicação, ou entre a formulação da regra e uma aplicação correta da mesma, é uma relação interna, pois esta é uma relação de dicto. A relação em questão aqui depende de como nós descrevemos as coisas. "Soma 2" é a formulação de uma regra que, se seguida na formação de uma série de números, terá na sua extensão “1000,1002, 1004, 1006,...", ou seja, esta é uma outra maneira de descrever a mesma coisa. É claro que uma regra pode ser entendida e eventualmente mal aplicada, assim como se pode ter uma habilidade $e$ eventualmente falhar no seu exercício adequado. Isto se dá porque seguir uma regra é uma noção que envolve a idéia de sucesso. Pode-se seguir a regra, mas

- Wittgenstein, Remarks on the Foundations of Mathematics (Blackwell, Oxford, 1978, 3. ed., trad. de G.E.M. Anscombe), p. 332. Citarei esta obra usando RFM.

7 Cf. Baker and Hacker, Wittgestein: Rules, Grammar and Necessity (Blackwell, Oxford, 1992), p. 179-

81. Citarei esta obra usando RGN.

- Cf. Glock, op. cit., p. 328. 
pode-se falhar. Mas isto não significa que haja aqui uma indeterminação, como esta que se apresenta quando consideramos que uma seqüência finita de números é compatível com um número infinito de séries de números (o ponto 3 no início do texto). Ora, porque esta compatibilidade não implica que de fato várias regras foram responsáveis pela formação da seqüência finita de números, pois o que este tipo de compatibilidade nos apresenta não é, como esclarece Glock, que uma regra deixa sua aplicação não determinada; mas ao contrário, que a extração de uma regra de uma seqüência é ela sim ou não determinada. Portanto, pode-se sem problemas aceitar que existe ligada ao conceito de seguir uma regra a possibilidade de falhar, esta não está logicamente excluída. O que se mantém, portanto, é que entender uma regra é saber como segui-la, o que exige saber o que the é conforme e o que a contradiz. Wittgenstein esclarece este ponto da seguinte maneira:

\footnotetext{
"Poderia ser perguntado: se todos os humanos que são educados desta maneira também calculam desta maneira, ou ao menos concordam que este cálculo seja o correto; então para que se precisa a leil?

[...]

O acordo das pessoas no cálculo não é um acordo de opiniões ou de convicçōes ${ }^{n 10}$.
}

As reticências nesta citação são ocupadas pelo trecho das RFM citado um pouco acima. Wittgenstein está esclarecendo nesta passagem qual é a função da lei, da regra, na obtenção de um resultado correto. O contraste crucial é entre a proposição empírica que diz que é assim ou assado que nós fazemos e a proposição gramatical que explicita o que é o correto. Dizer, portanto, que " $25^{2}=625$ " é enunciar uma verdade gramatical que exige que se alguém obtiver " $25^{2}=626$ " esta seja uma maneira errônea de elevar 25 ao quadrado ${ }^{11}$. Assim também é uma proposição gramatical a que esclarece a relação interna que há entre os seguintes dois termos: "a proposição de que o céu é azul é verificada pelo fato de que o céu é azul". E concordar a respeito desta relação interna não é o mesmo que concordar em opiniões ou convicções, mas somente reconhecer como falamos ou agimos.

Wittgenstein esclarece melhor ainda o que é uma relação interna na seguinte observação:

“Uma relação interna não é nunca uma relação entre dois objetos, mas tu podes chamá-la uma relação entre dois conceitos. $\mathrm{E}$ uma sentença afirmando uma relação interna entre dois objetos, assim como uma sentença matemática, não está descrevendo objetos mas construindo objetos"12.

É importante ter clareza sobre este ponto a respeito das relações internas. Não se trata de uma relação entre dois objetos ou eventos que seria uma relação

- Cf. Glock, op. cit., p. 327. Cf. também a p. 324 para o ponto sobre "seguir a regra" ser um "verbo de sucesso".

to RFM, p. 332.

"Cf. Wittgenstein, PI \#189. Este parágrafo é de compreensão muito difícil, portanto, vê o comentário de Baker e Hacker, RGN, p. 107-10.

12 Lectures on the Foundations of Mathematics, Cambridge 1939, ed. Cora Diamond (The University of Chicago Press, London, 1989), p. 73. Citarei esta obra usando LFM. 
normal como as outras, a saber, as externas, com a ressalva de que ela uniria os itens no mundo necessariamente. Ao contrário, a relação entre a regra “+ 2" e a série que resulta da sua aplicação "1002, 1004, 1006, 1008..." é uma relação estabelecida através de uma regra da gramática. Ou seja, não se trata de uma relação entre dois objetos ( neste caso presumivelmente duas entidades matemáticas), mas de um relação entre dois conceitos que se relacionam internamente, como na sentença: "a regra '+2' determina na sua $501^{\text {a }}$ aplicação o número 1002 ”. No caso de expectativas o ponto é mais claro, a relação interna está mais à vista: "a expectativa de que caia neve" é satisfeita pelo "fato de que cai neve". O aspecto de que a relação interna diz respeito à linguagem e conseqüentemente que 0 tipo de determinação que está em jogo aqui é sui generis são interligados para Wittgenstein.

"Uma vez que eu entendi a regra eu estou limitado no que eu farei a seguir. Mas é claro que isto só significa que eu estou limitado no meu julgamento sobre o que está de acordo com a regra e o que não están"

Conseqüentemente, devemos distinguir radicalmente as noçöes de determinação causal e de determinação gramatical. Como esclarece Stuart Shanker, a primeira noção é a de que algo produzirá um evento futuro, enquanto a segunda diz respeito a como "regras são formuladas para o uso de palavras"14.

\footnotetext{
"Ao concebermos uma forma de palavras como expressando uma regra, nós ipso facto concebemos certas outras formas de palavras como a especificação do que conta como concordando com a regra expressa desta maneira. Portanto, nós concebemos uma regra dada $\mathrm{e}$ os atos que dela se seguem como relacionados internamente. Isto é parte, ou um aspecto, do conceito mesmo de regra" ${ }^{15}$.
}

A citação das RFM menciona a "construção de objetos". É esta noção que deve ser entendida como uma "determinação gramatical". Mas esta noção de construção pode ser mal compreendida. Quando a questão diz respeito às relações internas em geral acredito que a "construção de objetos" a qual Wittgenstein se refere não passa da determinação de um conceito $^{16}$. Acho que este ponto já está suficientemente claro: o conceito da expectativa de que caia neve só é o conceito que é porque a expectativa é satisfeita pelo fato de que cai neve. No entanto, certas pessoas, por exemplo Norman Malcolm, parecem ter algumas dúvidas sobre estas relações internas e a "construção de objetos". Vou tentar esclarecer melhor a conexão entre regras e relações internas apresentando e combatendo as reflexões de Malcolm sobre o assunto.

13 RFM, p. 328-9.

14 "The Enduring Relevance of Wittgenstein's Remarks on Intentions" in: Hyman, John (ed.), Investigating Psychology, Sciences of the Mind after Wittgenstein (Routledge, London, 1991), p. 76.

15 Baker and Hacker, Language, Sense \& Nonsense (Blackwell, Oxford, 1984), p. 264. Citarei esta obra usando LSN.

${ }^{16}$ Cf. Shanker, op. cit., p. 80. Cf. também Baker and Hacker, LSN, p. 263-4. "Como tudo metafísico, relaçōes internas serao encontradas na gramática. Elas são criaturas das nossas práticas, pois resultam da maneira em que nós identificamos coisas, por exemplo pelo fato de que nós chamamos 144, e nada mais, o quadrado de 12" (Glock, op. cit., p. 190). 


\section{3- As dúvidas de Malcolm}

A minha pergunta-chave - como é que 0 aluno pode saber o que a ordem de formar a série de números somando 2 significa? - tem em Malcolm a seguinte formulação: "O que decide se um passo dado, uma apliçação particular feita, está ou não está de acordo com a regra?" E o ponto exato da dúvida de Malcolm é formulado por ele da seguinte maneira: "Esta questão não é respondida pela declaração de que a regra está 'internamente' relacionada com os atos que concordam com ela"17.

A minha resposta à pergunta-chave - de que o aluno pode saber o que +2 significa, e portanto saber que um passo dado está de acordo com a regra através de nossas explicações - só começa a ser esclarecedora para Malcolm se dermos devida importância à presença de uma comunidade de pessoas que age de acordo com regras, e isto como uma condição necessária à existência mesmo do fenômeno de seguir regras ${ }^{18}$.

Malcolm baseia esta posição sobre seguir regras em Wittgenstein num manuscrito do filósofo no qual ele, Malcolm, insere uma noção de construção. É claro que com a regra "+ 2 " os passos a serem tomados ou as aplicações da regra não foram já tomados ou as aplicações já feitas. Portanto, é claro também que se trata somente de um sentimento quando ao seguirmos uma regra temos a impressão de que as aplicações particulares da mesma já foram feitas, que elas existem antes de chegarmos a elas. Por isso Malcolm cita o manuscrito de Wittgenstein: "Uma regra não é uma extensão. Seguir uma regra significa formar a extensão de acordo com uma expressão 'geral". E Malcolm sobre isto comenta: "O que significa dizer que as aplicações de uma regra (sua 'extensão'), não são dadas com a regra, mas têm que ser produzidas; a extensão tem que ser construída"19.

Malcolm interpreta esta afirmação de Wittgenstein como significando que não pode ser a regra somente que determina o que é correto. Malcolm vai mesmo longe, a ponto de afirmar que a regra não determina nada a não ser a partir de uma situação em que há acordos não problematizados. Sem este tipo de situação a regra não é nada, "a regra, por si só, não determina nada" ${ }^{20}$.

A posição de Malcolm pode ser resumida na formulação "quando uma regra é dada a sua extensão não é dada" ${ }^{21}$.

Acredito que Malcolm está enganado nestas afirmações. Bem, é claro que, primeiramente, num sentido trivial quando uma regra é dada nunca a sua extensão é dada também. Wittgenstein não acreditava que o futuro nos é dado, embora

\footnotetext{
1" "Wittgenstein on Language and Rules" in: --: Wittgensteinian Themes, Essays 1978-1989 (Comell U.P., London, 1995), p. 148, local das duas citações.

18 Cf. Op. cit., p. 146. Malcolm diverge, no entanto, profundamente da visão "comunitarista" de Kripke: cf. Malcolm: "Following a Rule" in: --: Nothing is Hidden (Blcakwell, Oxford, 1986), p. 15481.

10 O texto de Wittgenstein é do MS 165, ca. 1941-44, p.78, traduzido por Malcolm ao inglês. $O$ texto de Malcolm é de "Wittgenstein on Language and Rules", p. 148, onde Malcolm cita o texto de Wittgenstein.

* Malcolm, op. cit., p. 150. Cf. também p.148-54, onde Malcolm combate a posição de Baker e Hacker, que sustentam que a regra e somente ela determina o que é correto.

21 Ibidem.
} 
em On Certainity ele afirme que o que chamamos "experiência que é a base para a nossa certeza", ou "a evidência de que algo vai acontecer", é a experiência passada. Portanto, é claro que, como o futuro, a extensão não é dada ${ }^{22}$. Se concebermos a extensão de uma regra como todos os casos de sua aplicação isto é óbvio e sem problemas. No entanto, e em segundo lugar, o problema está em que Malcolm não entende bem o que é uma regra. Este ponto já foi sugerido anteriormente, cabe agora articulá-lo explicitamente. Uma regra não é uma sua formulação. Por paridade de raciocínio, uma formulação da regra não é a regra ela mesma; mas é, como não poderia deixar de ser, uma formulação da regra. Nesta mesma linha, o que é a formulação de uma regra não é identificado por sua forma, mas antes por como certas expressões são usadas, isto é, como elas funcionam no conjunto das atividades humanas. Neste sentido, algo só expressará uma regra se for usado para expressar a regra ${ }^{23}$. Isto significa que em Wittgenstein regras são concebidas dinâmica ou funcionalmente, elas são instrumentos. "Algo é uma regra somente dinamicamente, somente na medida em que ela é usada de uma determinada maneira, viz. em práticas normativas, somente na medida em que ela esta envolvida desta maneira em práticas governadas por regras" ${ }^{24}$. Portanto, se a regra não é a sua formulação talvez haja a possibilidade de afirmar com Baker e Hacker que "se uma regra é dada, então também é dada a sua 'extensão"”25. Note-se que a palavra extensão está entre aspas. Isto tem uma razão de ser, pois como já afirmei num certo sentido nunca a extensão é dada com a formulação da regra. $\mathrm{O}$ que se deseja ressaltar aqui é o que está implicado em reconhecer que algo é de fato a formulação de uma regra ou o que significa entender uma regra. Como explicam Baker e Hacker numa passagem que vale a pena ser citada inteira:

"Um símbolo que é usado para formular uma regra é entendido somente se ele é tomado como sendo uma formulação da regra, de fato somente se ele é entendido como formulando uma regra particular. Quando nós damos a alguém um padrão para copiar ou pedimos a ele para construir a série de acordo com a regra " $0,2,4,6,8, \ldots$ " nós não julgamos que ele entendeu a instruçăo meramente porque ele olha para ele, ou meramente se ele entende os numerais "0", "2", "4", " 8 ", independentemente do que ele faz. Seu entendimento (ou falta dele) é manifesto nas suas ações, no que ele copia ou escreve, em como ele emprega a formulação da regra como padrăo de correção. [...] É um critério para a incompreensão da regra " $0,2,4,6,8, \ldots$ " que alguém escreva " $12,20,45$ " como os três termos seguintes. Se ele entende a regra, ele deve escrever "10,12,14" como os próximos termos.

22 Cf. On Certainty (Blackwell, Oxford, 1979; ed. G.E.M. Anscombe e G.H. von Wright, traduzido ao inglês por Denis Paul e G.E.M. Anscombe), \# 275. Cf. também Suart Shanker, op. cit., p.76-8 sobre porque o tempo, o futuro, são irrelevantes para as relações internas. Deve-se distinguir, no entanto, entre uma regra e as suas aplicações por parte de um seguidor da regra. Por exemplo, há a distinção entre formar a intenção de fazer $x$ e 0 agir que é levar a intenção a cabo, $e$ aí cabe falar de tempo. Mas não quando se trata de saber que a intenção de fazer $x$ é satisfeita pela ação de fazer $x$. Por isso, deve-se também tomar cuidado com a relação da causação com a ação: pois, pode que nossas razōes para fazer $x$ sejam a produçäo de $x$, mas será a ação que terá este efeito $e$ não as nossas razöes ou intenções (cf. Loc. cit.). "Regras nos guiam, nos dizem, de fato determinam, o que deve ser feito. Nós mesmos determinamos o que é feito" (Baker and Hacker, LSN, p. 259). Cf. Baker e Hacker, RGN, p. 41-52.

Op. cit., p. 47. Cf. também Glock, op. cit., p. 324, que explica bem que é extremamente importante entender que a função normativa não é redutivel à forma lingüística usada para realizar tal funçăo. Cf. ainda as p. 151-2.

RGN, p.243. 
Não há uma necessitação misteriosa aqui (ele poderia dizer que ele tem coisas melhores para fazer!). 0 "deve" marca a determinação de um conceito. Escrever aqui qualquer outra coisa que " $10,12,14$ " não é o que é chamado seguir a regra " $0,2,4,6,8, \ldots$ " [...], e portanto é também um critério para não entendê-la. [...]

O aparente abismo lógico que há entre a regra e a sua "extensão" surge da pressuposição errônea de que entender uma regra é ao menos parcialmente independente de como se projeta a mesma em ações. Mas não importa a maneira como ela é formulada ou explicada, uma regra só é entendida se ela é projetada corretamente. Ser ignorante ou estar enganado sobre quais atos estão de acordo com ela é ser ignorante ou estar enganado sobre o que é a regra. Entender a regra é saber que atos concordam com ela e quais a violam (assim como entender uma proposição é saber o que é o caso se ela é verdadeira)" ${ }^{\prime 2}$.

Eu acredito que Malcolm se fia na pressuposição errônea mencionada por Baker e Hacker, esta que cria o aparente abismo entre a regra e a sua "extensão". Acredito que Malcolm se fia em parte na noção de que compreender a regra é algo que está "com o indivíduo", como um estado num determinado momento, exigindo somente que este algo seja balizado comunitariamente. Esta é uma idéia que acredito estar por trás de suas reflexões finais no texto "Wittgenstein on Language and Rules" ${ }^{27}$. Malcolm insiste que palavras não podem significar o que um indivíduo "pensa que elas significam", e que um uso correto não é possivelmente alguma coisa que um indivíduo faz com um signo. O que me parece estar sendo equivocadamente pressuposto por Malcolm nestas considerações é que qualquer coisa que um indivíduo faça é o resultado do que o indivíduo pensa, com todas as implicações de subjetivismo em relação a este pensar. Por isso Malcolm exige: "Deve haver um uso de um signo que é independente do que um falante individual faz com ele, a fim de que o uso do signo por parte deste último seja correto ou incorreto". E Malcolm cita Benjamin Armstrong Filho com aprovação: “'A maneira de usar um signo' independentemente, que é exigida para a satisfação das condições de um uso correto, não pode ser oferecida por um indivíduo singular". Malcolm, então, comenta: "Esta condição de independência pode ser satisfeita somente se existe uma comunidade de falantes que usam o signo de uma maneira costumeira". Por fim Malcolm cita Wittgenstein sobre "saber o significado" de uma palavra: "Saber o seu significado é usá-la da mesma maneira que outras pessoas a usam"2s.

Malcolm, no entanto, está errado a este respeito, e a sua citação de Wittgenstein é mal feita tendo em vista o seu propósito "comunitarista". Note-se que o que Wittgenstein mesmo frisa, e que nas notas de Bosanquet, Rhees, Smythies e do próprio Malcolm é posto em itálico, é "da mesma maneira", e não "que outras pessoas". Além disto, o trecho citado é antecedido pelas seguintes observações: "Até parece que o teu aprender como usá-la [a palavra "boo"] seria diferente do teu saber seu significado. Mas o ponto é que nós todos fazemos o MESMO uso dela"29. Embora toda a última sentença esteja em itálico, a palavra "mesmo" é que

* RGN, p. 97.

Op. cit., p. 170-1.

0 texto de Wittgenstein está nas LFM, p. 183; as citações de Malcolm estão à p. 171.

Loc. cit. 
está em maiúsculo, e não as palavras "nós todos". O ponto aqui diz respeito à noção de prática, de técnica, que aparece nas reflexões de Wittgenstein. Eu não perseguirei aqui esta discussão por falta de espaço e por considerá-la resolvida contra Malcolm. "A mesma maneira", "fazer o mesmo", dizem respeito a uma técnica ou prática que é compartilhável entre os membros de uma mesma comunidade e não necessariamente compartilhada. Portanto, pode tratar-se inclusive da ação de um eventual Robinson Crusoé, o que importa é a técnica, o fazer de algo que é o mesmo. Falar em técnica ou prática neste contexto - de seguir regras implica em que esta técnica depende da existência de algo que na ação do sujeito conta como estar de acordo ou em conflito com a regra. O domínio de uma técnica se manifesta em ações, na prática, no fazer de certa coisa. "Uma técnica é exibida num padrão de comportamento ou atividade. [...] Técnicas de seguir regras, [...] é de sua essência elas serem empregadas na prática, nas transações diárias com pessoas e com objetos no mundo"30. É por isso que Baker e Hacker observam que "não há tal coisa como um jogo-de-linguagem 'privado', ou algo análogo a um jogo-de-linguagem subjetivo,31. Note-se que a palavra "privado" está entre aspas, o que significa que não se trata de privado no sentido costumeiro, a saber, de pertencente a um indivíduo, de algo não compartilhado; mas, ao contrário, trata-se de algo não compartilhável, que por princípio não pode ser compartilhado. Este ponto pode ser entendido através das reflexões de Wittgenstein sobre máquinas de costura [sic]. Para Wittgenstein algo somente será uma máquina de costurar, inclusive privada - agora no sentido de pertencer a um indivíduo - se este algo merecer ser chamado de máquina de costurar, e isto somente acontecerá se este algo for parecido com outras máquinas de costurar. Portanto, o ser privado ou não, o pertencer a um indivíduo ou não, não acrescentará nada ao seu estatuto de máquina de costurar. Baker e Hacker resumem o ponto: "Até mesmo uma técnica privada precisa satisfazer os critérios para ser uma técnica e, na medida em que faz isto, ela será uma técnica perfeita apesar de ser não compartilhada" ${ }^{32}$.

É por estas razões que Baker e Hacker comentam sobre a noção de determinação e sobre a idéia de que os passos estão já determinados pela fórmula que expressa a regra: "É deveras importante reconhecer que isto não é errado. É errado somente sob a égide de uma incompreensão de determinação". E para justificar este ponto eles citam um trecho de "The Language of Sense Data and Private Experience": "Quando tu tiras da cabeça a imagem de 'estar determinado', então

* Baker e Hacker, RGN, p. 163. Cf. também p. 154-81, onde se insiste que "prática social" não é um pleonasmo. Cf. também Glock, op. cit., p. 327-9; e Budd, M., Wittgenstein's Philosophy of Psychology (Routedge, Londres, 1989), p. 39-42. Cf. ainda Saugstad, J., "Kant on Action and Knowledge" in: Kant-Studien (Heft 3, 1992), p. 270-84, que apresenta uma interpretação wittgensteiniana de Kant em termos "externalistas" que fazem referência a nossa habilidade de realizar ações visíveis e observáveis envolvendo essencialmente o movimento do corpo humano.

11 RGN, p. 176. Cf. também as p. 164-5 sobre a objetividade vinculada com o domínio de uma técnica. $\mathrm{O}$ ponto diz respeito a como algumas coisa que um indivíduo faz com um signo são usos corretos do mesmo, o que permite a distinção entre pensar estar-se seguindo uma regra e de fato seguí-la. Assim impugna-se a propriedade do pressuposto de Malcolm sobre o que um indivíduo não pode conseguir fazer devido a um suposto inescapável subjetivismo que o acompanha.

a Op. cit., p. 178. Wittgenstein fala da máquina de costuras no MS 166, p. 7, citado por Baker e Hacker, loc. cit.. Este ponto é crucial, pois nem tudo que parece uma técnica de fato é uma. 
tu te livras da perplexidade. Entretanto, a gente pode dizer que a expressão algébrica determinou suas ações - e de uma maneira perfeitamente correta. Mas agora tu te livraste da cäibra"”33.

É com estas considerações que pretendo estar deixando claro por que é correto e portanto aceitável dizer que "a regra e nada senão a regra determina o que é correto"34.

\section{4- Normatividade e habilidades humanas}

O objetivo até agora foi mostrar que, contra o ceticismo semântico e o seu acompanhante, o comunitarismo, regras são o que determina o que está de acordo e o que não está de acordo com as mesmas. Minha conviç̧ão é a de que a aceitação deste ponto depende de um entendimento adequado das "relações internas" em Wittgenstein. Foi este entendimento que procurei oferecer até aqui. Foram apresentados alguns aspectos importantes da noção de relação interna. Nesta última seção quero tematizar certos pontos que ainda podem ser objeto de suspeição. Há conexões no que eu disse que podem parecer frágeis, e que portanto podem sugerir que o problema a respeito de como regras funcionam não foi resolvido. Cabe agora explicitar o que significa dizer que relações internas são criaturas de nossas práticas. Voltarei a frisar algumas distinções já feitas, mas uma outra distinção aparecerá como importante: entre práticas internas aos fenômenos normativos e práticas que lhes estão à base. $O$ que espero é que $o$ efeito sobre $o$ leitor do quadro que será apresentado seja 0 de satisfação intelectual, pois afinal de contas silenciar a dúvida cética através da argumentação é resolver o problema filosófico ${ }^{35}$.

A preocupação de alguém como Malcolm, e de "comunitaristas" em geral, é com uma distinção que ninguém duvida tem que ser feita: entre pensar que se está seguindo uma regra e segui-la de fato. O problema é a importância que é dada a ela, ou melhor, a posição que se atribui a ela na descrição e nas considerações sobre fenômenos normativos: instruir, seguir regras, justificar, corrigir, etc. Para Malcolm ancorar esta distinção em algo que seja realmente firme é o que se pode fazer de mais importante ${ }^{36}$.

Mas, se regras são o que diz o que está conforme a regra e o que a contraria, como tentamos mostrar, então pode-se saber que se está seguindo a regra ou que apenas se pensa que se está seguindo a regra por apelo à regra simpliciter. Regras são, neste sentido, instruções às quais também podemos apelar para justificar nossas ações, de maneira tal que toda a subjetividade que atormenta Malcolm e os comunitaristas pode ser eliminada. Seguir uma regra é agir de uma forma tal que esta ação satisfaça os critérios de correção internos à técnica ou prática de seguir

* RGN, p. 110. O trecho de Wittgenstein está na obra mencionada à p.24 da edição original (in: Klagge, J. e Nordmann, A. (ed.): Ludwig Wittgenstein: Philosophical Occasions, 1912-1951 (Hackett Publishing Company, Cambridge, 1993) que tem a paginação original).

* Baker e Hacker, op .cit., p. 172.

Cf. Glock, op. cit. p. 341.

Cf. Malcolm, "Wittgenstein on Language and Rules", p. 171. 
a regra em questão. Ora, não satisfazer estes critérios pode eventualmente se pensar que se está seguindo a regra desejada quando na verdade não se está. 0 ponto principal, no entanto, é que saber que não se está seguindo a regra está à disposição de um indivíduo. Dominar uma técnica de seguir uma regra é algo que está objetivamente presente no que um indivíduo faz ${ }^{37}$. Portanto, voltando ao nosso aluno. Ele pode saber, ele próprio, que escrever "1000, 1004, 1008,..." não é seguir a regra "+ 2". É claro que ele pode somente pensar estar seguindo a regra "+ 2", mas suas próprias reflexões sobre como a regra the foi ensinada, sobre quantas unidades estão entre os primeiros nos da série, e sobre outras tantas coisas, podem fazer com que ele veja que errou. Aliás, o chamamento à ordem por parte de um membro da comunidade muitas vezes faz exatamente isto: chama 0 indivíduo à reflexão - a sua - sobre o que ele fez ("Pensa bem no que tu fizeste!").

A verdade é que assim como o sentido de expressões como "isto me parece vermelho" é derivativo em relação a expressões como "isto é vermelho", assim também acontece com o par "penso que sigo a regra" e "sigo a regra" ou com o par "ele pensa que segue a regra" e "ele está seguindo a regra". É claro que é possível que alguém se engane e esteja somente pensando estar seguindo uma regra; o que isto supõe, no entanto, é que enganos, erros e infelicidades são assim caracterizados porque a regra e o comportamento relevante em seguir-se a regra podem ser identificados por algum - inclusive o próprio - participante na prática de seguir-se esta regra. $\mathrm{E}$ isto não é uma exigência advinda de uma conjectura teórica, mas é o que se requer quando concebemos seguir uma regra como um conhecimento prático ${ }^{39}$. É por isso que a distinção entre pensar seguir e seguir um regra não é tão primitiva do ponto de vista lógico como acredita Malcolm. Não é primeiramente 0 problema que 0 desrespeito desta distinção poderia representar que está por trás do apelo wittgensteiniano à prática. Ao contrário, entender o que seguir uma regra significa é que precisa da noção de prática. Vejamos.

$\mathrm{O}$ que Wittgenstein tem em mente quando ele insiste que "“obedecer à regra' é uma prática” (PI \#202) certamente não é o que Malcolm imagina. Insistir na importância da prática nas reflexões de Wittgenstein sobre seguir regras não exige que se conceba esta prática como a prática de uma comunidade, que então poderia ligar regra e a aplicação correta da mesma. Não há em Wittgenstein este tẹtium quid ${ }^{40}$. A referência à prática no texto citado tem o objetivo de indicar que "obedecer a uma regra" é uma expressão que se aplica a alguma coisa que se faz, e isto, como já tentei esclarecer, no contexto de uma técnica, de uma regularidade de comportamento, na qual se faz o mesmo. Ou seja, o que importa aí é uma prática, um regularidade, normativa, esta cuja manifestação não é desvinculada do que nós chamamos "seguir a regra". "Não há tal coisa como uma formulação da regra independentemente do uso de expressões em... atividades normativas (i.e. ser uma formulação da regra é ser usada de tais e tais maneiras) ${ }^{\text {,41 }}$. É por isso

Cf. Baker \& Hacker, RGN, p. 164.

Cf. Wittgenstein, Zettel (Blackwell, Oxford, 1981, 2. ed.; editado por Anscombe e von Wright e traduzido ao inglês por Anscombe), \#\#20-35.

m

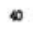

41

Cf. Baker \& Hacker, LSN, p. 258, n. 24.

Cf. Baker \& Hacker, RGN, p. 180.

Baker \& Hacker, RGN, p. 134. 
também que quando em Wittgenstein há a necessidade de alguém ser treinado, como no caso do nosso aluno, quando se fala em dar explicações, instruir alguém sobre como seguir a regra, esta noção traz consigo a idéia de introduzir alguém numa atividade normativa. A pessoa aprende o que fazer, isto num contexto em que se deixa claro também o que deve ser feito, ou seja, o que é chamado "correto", do que está de "acordo com a regra", etc.

Por estas razőes, "prática" em Wittgenstein é a noção de uma prática normativa nos termos expostos, e não de uma prática necessariamente social. Numa imagem de Baker \& Hacker: o contraste que interessa a Wittgenstein não é aquele entre uma ária e um coral, mas entre a partitura e o cantar de uma ária ${ }^{42}$. E entender este contraste é saber que uma partitura não é o que é sem o cantar em geral, seja de uma ária ou de um coral.

Insistir neste ponto da posição de Wittgenstein, de que o que importa são técnicas, práticas, atividades normativas, deixa claro por que ele citava, referendando, a expressão de Goethe: "No começo era a ação". A preocupação de Wittgenstein com práxis nestes parágrafos das PI (198-205), dos quais o problema filosófico é o de seguir uma regra, mostra o lugar de destaque que a ação tem na sua filosofia. Ao contrário de Descartes, para quem o pensar era chave, para quem o entretenimento de um símbolo na mente era o fundamental, Wittgenstein resolve o problema ao mostrar que o entender de uma regra somente é exibido numa atividade que está inserida numa regularidade normativa, isto é, numa técnica de aplicar regras, esta que não passa de uma habilidade prática que só é exibida, redundantemente, em ações. Quando apresentado com o problema filosófico de saber como fazer a transição de experiências para palavras, como, por exemplo, "como eu sei que esta cor é o vermelho?" (cf. PI \#381), do qual a solução não parece simplesmente poder ser "eu aprendi português", Wittgenstein observa: "[...] No final eu tenho que dar o salto. Eu devo dizer 'isto é vermelho' ou agir de alguma maneira, o que implica fazer a mesma coisa" ${ }^{43}$.

É compreensível, portanto, que Wittgenstein veja a linguagem como um refinamento, que ele referende que no começo era a ação e que afirme que o que ele chama de jogo-de-linguagem tenha sua origem e forma primitiva na reação ${ }^{44}$. É a ação que em Wittgenstein é fundamental.

"Uma linguagem é uma forma de ação humana, tem suas raízes na conduta humana. Não surge fundamentalmente de nenhum tipo de raciocínio que lhe é anterior. Falar é agir, e o uso de palavras e sentenças está entrelaçado com o agir humano que tem lugar no mundo do qual fazemos parte. $\mathrm{O}$ uso de uma linguagem é parte de uma forma de vida.

[...] É o agir de acordo com regras, a prática de uma conduta normativa, que está na base de nossos jogos de linguagem. A linguagem, longe de ser um reflexo do pensamento, é uma forma de conduta"

42 Cf. RGN, p. 151.

- Este texto é do MS 129 e está às páginas 116 e seguintes. Ele é citado por Baker \& Hacker, RGN, p. 148.

4 Cf. Wittgenstein Culture and Value (Blackwell, Oxford, 1980; editado por von Wright e H. Nyman, traduzido ao inglês por P. Winch), p. 31 .

4 Souza, Danilo M. de, "Ceticismo Semântico" (Manuscrito, v. 11, n. 2, out. 1988), p. 108. 
Este é um aspecto da luta de Wittgenstein contra o racionalismo na explicação do entendimento e do uso da linguagem. Na discussão de Wittgenstein do jogo-de-linguagem dos construtores no começo das PI ० Wittgenstein-interlocutor pergunta: "Mas como ele sabe onde e como ele deve informar-se sobre a palavra 'vermelho' e o que ele deve fazer com a palavra 'cinco'?"; e Wittgenstein responde: "Bem, eu assumo que ele age como eu descrevi. Explicações chegam a um fim em algum lugar" (\#1). O ponto de Wittgenstein é que é a regra ela própria que serve de guia, e não a série possivelmente infinita de interpretações interpostas entre a regra e minha ação, série que acaba sendo postulada pelo racionalista que sempre pede mais uma razão para a ação. "[...] Nós olhamos para a regra para sermos instruídos e fazemos algo, sem apelar para nada diferente para nos guiar" (PI \#228). Quando sabemos qual é a regra, o que ela exige, o que é o mesmo que dominar a técnica de aplicação da regra, nós simplesmente reagimos, mas é importante não confundir, como já alertei, a respeito deste "passo" o que é causa e o que é razão. Nós agimos, nós determinamos o que é, razões não são nem precisam ser causas, e é isto que Wittgenstein quer frisar quando esclarece:

\footnotetext{
"E o erro que nós aqui e em mil outros casos parecidos estamos inclinados a cometer é marcado pela palavra 'fazer' como nós a usamos na sentença 'Não é nenhum discernimento ['insight'] que nos faz usar a regra como o fazemos', porque há a idéia de que 'algo deve fazer a gente' fazer o que nós fazemos. $\mathrm{E}$ isto novamente ajunta-se à confusão entre causa e razão. Nós näo precisamos de nenhuma razão para seguir a regra como nós fazemos. A cadeia de razões tem um fimm.
}

Note-se que o racionalismo apresentado desta maneira recebe o mesmo combate que 0 ceticismo sobre seguir regras ${ }^{47}$. Contra o ceticismo estabelece-se que as reações em geral não são o fruto do fato de que cada um de nós tem razões suficientes para acreditar que é isso que ele deve fazer ou dizer, estas reações não são baseadas na razão como uma faculdade de raciocínio ou inferência.

Há aqui, no entanto, a possibilidade de um outro mal-entendido. Este diz respeito ao acordo que se encontra nesta base dos jogos de linguagem, este que é o acordo na ação, na reação, e isto pode sugerir que esta regularidade é a noção fundamental para se entender seguir regras. E é aqui que se apresenta uma concepção tentadora, mas errada: a base da normatividade seria a identidade na reação. A idéia seria a de que só temos o seguir objetivo de uma regra particular porque nós reagimos da mesma maneira, seria nisso que se poderia fundamentar 0 consenso que é o critério para a correção na aplicação da regra na visão 'comunitarista'. Mas isto está errado, e tomar ciência disto depende de entenderse a noção de framework ou background em Wittgenstein. Optarei pela tradução armação, que deve ser tomada no sentido em que, por exemplo, a armação de ferro dá estrutura ao concreto armado.

Wittgenstein no parágrafo 198 das PI se pergunta sobre a relação que há entre a expressão de uma regra e ações. Ele observa que normalmente se é treinado a reagir à expressão, ao signo, de uma determinada maneira; e quando me é apre-

\footnotetext{
The Blue and Brown Books (Blackwell, Oxford, 1969), p. 143

Cf. Budd, op. cit., p. 42-5.
} 
sentado o signo "eu reajo a ele de tal maneira". Pode-se pensar que é nesta reação de comportamento, que deve ser a mesma, que deve ser normal, ou seja, do mesmo tipo que a da maioria, que podemos basear a objetividade no seguir-se uma regra. Mas, não é este o ponto de Wittgenstein. "Eu reajo a ele de uma tal maneira" é decisivo somente no contexto da existência de um uso regular do signo, da existência daquilo no qual fui treinado. Wittgenstein comenta:

\footnotetext{
"Mas isto é importante, a saber, que esta reação, que é a garantia da compreensão, pressupõe como um ambiente circunstâncias particulares, formas de vida e fala particu-

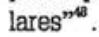

Este é o contexto normativo no qual uma reação qualquer deve se inserir para que ela conte como uma aplicação da regra. Mas há algo que está à base dos vários contextos normativos, que no entanto não os fundamenta ou justifica, mas que é a condição para que haja contextos normativos em geral: a armação. Esta noção aparece no parágrafo 240 das PI:

\footnotetext{
"Disputas não surgem (entre matemáticos, digamos) sobre a questão de uma regra ter sido obedecida ou não. As pessoas não brigam por isso, por exemplo. Isto faz parte da armaçăo na qual se baseia o funcionamento da nossa linguagem (por exemplo, ao oferecerem-se descrições)".
}

O problema em relação à noção de armação é dar-lhe o lugar correto na descrição dos fenômenos normativos. Como pode-se esperar, até mesmo o comunitarismo mais elaborado de Malcolm erra nesta empreitada. Ele afirma que, "sem um consenso de ação e reação, não haveria conceitos, linguagem, regras. É irrelevante se a gente chama este consenso uma 'pressuposição', uma 'conđição', ou parte da 'armação da linguagem'". Malcolm, conseqüentemente, acredita que é este consenso que poderá evitar um desacordo generalizado sobre a aplicação de regras, e ultimamente garantir a aplicabilidade da distinção que lhe é tão cara entre pensar que se segue a regra e segui-la ${ }^{49}$. Mas o que Malcolm pensa que é irrelevante não é de fato nada irrelevante. Sob pena de afinal perder-se a força da regra - mesmo embora o comunitarismo de Malcolm não pressuponha, por exemplo, que se vote antes de seguir uma regra - é crucial a distinção entre as condições de normalidade nas quais os jogos de linguagem são jogados e as articulações gramaticais internas aos jogos.

Condições de normalidade dizem respeito a como o mundo é. Os objetos no mundo não mudam de cor a todo momento. Estes mesmos objetos não mudam de tamanho incessantemente. Se o mundo, ou seja, os objetos no mundo não se comportassem com constância seria muito difícil imaginar o propósito de se falar de cores, por exemplo. Imagina qual poderia ser o propósito de se medir o comprimento de objetos se eles aumentassem e diminuíssem caprichosamente. Se pêndulos, mecanismos de relógios e até mesmo o quartzo não funcionassem do mesmo modo que outros pêndulos, mecanismos e quartzos, não haveria medição de tempo. Condições de normalidade, portanto, são constâncias no mundo natural.

\footnotetext{
RFM, p. 414
}

- Cf. Op. cit., p. 156 para a citação e o ponto mencionado. 
Por causa desta noção de condiçōes de normalidade Wittgenstein escreve: "É como se nossos conceitos envolvessem andaimes de fatos"

O que é importante que se note, em primeiro lugar, é que estes fatos também incluem fatos sobre nós, seres humanos. As condições de normalidade dizem respeito à relativa estabilidade do mundo, do qual nós, com a nossa natureza, também fazemos parte. Nossas capacidades discriminatórias em relação à audição, ao tato e aos demais sentidos são sem sombra de dúvidas uma precondição para os nossos conceitos de propriedades detectadas por estes sentidos. Até mesmo nossas propensōes para certas ilusões sensoriais são necessariamente pressupostas se quisermos fazer a distinção entre o que é somente aparência e 0 que é realidade. $\mathrm{E}$ à nossa natureza relativamente estável também pertencem nossas capacidades mentais e nossas reações de cunho emocional mais primitivas (cf. PI \#142).

O ponto fundamental, no entanto, em relação a esta noção de condições de normalidade, aos vários acordos e constâncias que existem no mundo natural que inclui a nós seres humanos, é a sua posição lógica como algo que pertence à armação. Condições de normalidade não são inscritas nas regras dos vários fenômenos normativos nos quais nós nos exercitamos. Quero discutir dois exemplos para provar este ponto.

Embora possa parecer assim, a palavra vermelho não significa o que parece vermelho em condições normais de percepção, nem o que reflete raios luminosos com X comprimento de onda. Vermelho significa, por exemplo, a cor de um tomate maduro. Isto é verdade porque a constância pressuposta - a do mundo e a nossa - não entra na explicação que nós damos do significado de uma palavra. Condições normais de percepção, que dizem respeito ao mundo e a nós, são pressupostas para que vejamos as coisas como elas são, incluindo as suas cores, e vermelho é a cor de algumas destas coisas ${ }^{51}$.

Assim também acontece com jogos em geral. Não faz parte das regras do futebol que o jogo seja jogado num local com a força gravitacional e a inércia da terra. Saber as regras do futebol não envolve saber o que são força gravitacional e inércia, por exemplo. Se condições de normalidade fizessem parte das regras - e portanto das relações gramaticais entre conceitos que são aplicados às nossas atividades normativas - então qualquer "jogador" do jogo deveria também saber 0 significado dos termos que descrevem as condições de normalidade.

Wittgenstein marca a diferença que há entre o que pertence à armação e o que pertence à gramática ou conjunto de regras de uma determinada atividade normativa muito bem:

“O acordo dos humanos que é a pressuposição da lógica não é um acordo de opiniōes, muito menos em opiniões sobre questões de lógica ${ }^{62}$.

Foi dito: 'É uma queståo de consenso geral'. Há algo de verdadeiro nisto. Mas - no que é que nós concordamos? Concordamos nós sobre a proposição matemática, ou em obter este resultado? Estas são coisas inteiramente diferentes.

\footnotetext{
Zettel, \#350.

61 Cf. Zettel, \#\#418 e ss.

s2 RFM, p. 353.
} 
Sobre o que é que eles precisam concordar? Eles concordam em obter isto. (...) Eles concordam no que eles fazem.

A verdade matemática não é estabelécida através da concordância de todos sobre ela [a proposição matemátical ser verdadeira - como se eles fossem testemunhas disto. Porque todos concordam no que eles fazem, nós a tomamos como uma regra, e a colocamos nos arquivos. Nảo chegamos à matemática antes de fazermos isto ${ }^{53}$.

[...] As verdades da lógica são determinadas por um consenso de opiniões. É isto que eu estou dizendo? Não. Não há nenhuma opinião; não é uma questão de opinião. Elas são determinadas por um consenso na ação: um consenso em fazer a mesma coisa, reagir da mesma maneira. [...] Nós todos agimos da mesma maneira, caminhamos da mesma maneira, contamos da mesma maneira ${ }^{n \in 4}$.

É porque há a distinção em questão que nós não precisamos ensinar a uma criança como ela deve entender o nosso gesto de apontar para algo numa definição ostensiva (note-se que gatos, por exemplo, não tirariam os olhos da nossa mão). É também por isso que Wittgenstein afirma, no caso de provas da matemática, que "a concordância nas ratificações é uma precondição de nosso jogo-delinguagem, ela não é afirmada nele" ${ }^{\text {55 }}$.

Portanto, a pressuposição da lógica é uma série de acordos que não passam de condições de normalidade sobre como o mundo e nós funcionamos. São estas condições que tornam possível a normatividade; mas elas não determinam, nem a justificam. As condições de normalidade são apresentadas por Wittgenstein como naturais, mas não como necessárias. A rigidez do dever lógico pertence ao jogode-linguagem e não à armação, portanto nem fará sentido dizer que conđições de normalidade são necessárias. Só será necessário o que pertence às regras do jogo, e como vimos, isto não acontece com as condições de normalidade ou com a armação. A lógica não é abolida por ter como pressupostos uma série de fatos (cf. PI \#242). A formação de conceitos é de fato condicionada causalmente, mas isto não é uma imposição sobre a lógica: A lógica não responde aos fatos da natureza. Este é um tema importante em Wittgenstein: a autonomia da gramática. Condicionamentos causais não podem determinar ou até mesmo modificar o estatuto de, por exemplo, movimentos no jogo de xadrez, passando-os de lícitos para lícitos ou vice-versa. É claro, no entanto, que ninguém jogaria xadrez com peças que pesassem toneladas e toneladas.

Os fatos da natureza que constituem as condições de normalidade também não justificam as regras que pertencem aos jogos-de-linguagem ou às atividades normativas. A necessidade que há em "xeque-mate é o último movimento de um jogo de xadrez" não presta contas à realidade, ao mundo.. Não há nada no mundo que, numa espécie de causação necessária, nos determinaria a continuar aceitando aquela afirmação sobre o xeque-mate, nem a aceitá-la como correta. Um certo naturalismo que há em Wittgenstein diz respeito à armação e não é de cunho justificatório, porque tudo o que é necessário tem a ver com a linguagem e esta é uma criação humana, fruto da arbitrariedade dos homens e mulheres.

\footnotetext{
LFM, p. 107.

Ibidem, p. 183-4.

65 RFM, p. 365; cf. também p. 323. Cf. ainda Zettel, \#\#429-31.
} 


\section{5 - Conclusão}

O objetivo principal deste artigo foi expor parte da gramática da noção de regras. $O$ aspecto mais importante foi o de que regras são eficientes na "força normativa" que possuem. Apreciar isto, no entanto, requer que se veja que regras não são formulações ou até mesmo estados de um indivíduo. Elas são instruções, padrões, justificativas dentro de um contexto normativo no qual existem técnicas de se fazer algo que é visto como o mesmo. Só será uma regra o que funcione como tal. A noção de prática, de técnica, foi muito importante no desdobramento do que significa dizer estas coisas. Práticas e técnicas foram na seqüência distinguidas de práticas e reações que estão à base dos nossos jogos-de-linguagem. Gostaria de terminar este artigo elaborando um pouco mais a noção de normatividade, com vistas, no entanto, no que pode e deve ser o esclarecimento filosófico a respeito dos conceitos discutidos aqui.

É certo que uma regra não se confunde com uma sua formulação, mas isto não deve induzir-nos a conceber regras como entidades platônicas. Embora um formulação da regra não seja a regra, assim como uma sentença não é a proposição, devemos, no entanto, notar que onde nenhuma formulação da regra for possível, então também não fará sentido falar-se da existência de uma regra. Isto porque não será possível conceber como um indivíduo pode usar tal regra para guiar sua conduta, avaliar o que fez como correto ou o contrário, e ensinar alguém a falar algo. $O$ ponto diz respeito ao fato de que não faz sentido atribuir comportamento normativo a seres não dotados de linguagem. Há comportamentos de animais que certamente parecem normativos. Animais parecem querer corrigir uns nos outros comportamentos desviantes através, eventualmente, da agressão. Mas estes comportamentos estão muito distantes de comportamentos humanos de seguir regras. Seres humanos não são só agressivos à maneira dos animais, eles também justificam seus comportamentos, eles consultam regras para se guiarem, e eles corrigem e criticam seus comportamentos apelando para regras. Normatividade parece estar inseparavelmente ligada ao uso da linguagem, ao uso de símbolos.

Esta idéia de que a normatividade necessita do uso da linguagem pode sugerir que na tentativa de se obter uma compreensão dos fenômenos normativos deve-se distinguir diferentes capacidades e então procurar a mais fundamental. Isto é uma espécie de reducionismo. Wittgenstein resiste a esta linha de pensamento. Em primeiro lugar, seguir uma regra - isto que é a marca da normatividade - está ligado à possessão de diversas capacidades, sem no entanto se identificar, via definição, com nenhuma em particular. As capacidades de ter intenções e de ter uma linguagem são interligadas numa grande medida. E no caso das intenções Wittgenstein não tentou reduzí-las a algo mais fundamental, como, por exemplo, um estado mental.

"Nosso erro é buscar uma explicação quando deviamos olhar para o que acontece como um 'proto-fenômeno'. Isto é, quando deviamos ter dito: este jogo-de-linguagem é jogado (PI \#654).

Não se trata de explicar um jogo-de-linguagem através de nossas experiências, mas de registrar [Feststellung] um jogo-de-linguagem" (PI \#655). 
O ponto de Wittgenstein aqui é ressaltar que só compreenderemos se olharmos "para o jogo-de-linguagem como o primário" (PI \#656).

Em segundo lugar, o conceito mesmo de seguir uma regra com todas as suas expressões (todos os diversos casos em que dizemos que alguém está fazendo isto) é o mais fundamental. Usar símbolos supõe seguir regras. Por conseguinte, "o princípio que deve nos guiar ao tentarmos esclarecê-lo (o conceito de seguir regras) é evitarmos cavar abaixo dele na esperança de descobrir conceitos mais básicos sobre os quais ele se baseia e aos quais é redutível. A rede de conceitos normativos será esclarecida traçando-se suas reticulações, o padrão das relações internas, não cavoucando-se por baixo deles na busca de fundações"so ${ }^{\text {. Devemos }}$ nos convencer, em função da autonomia da gramática, que não é possível quebrar o círculo de noções normativas "desde fora", pois os conceitos que nos perturbam estão interligados horizontalmente das formas que foram toscamente indicadas ${ }^{57}$. Mais argumentos são necessários aqui para mostrar por que articulações gramáticas são horizontais, destas que segundo Wittgenstein conectam sem mistérios a linguagem e o mundo, mas estes não podem ser apresentados aqui. Entretanto, faz parte do que se pode fazer aqui que não se possa dizer tudo ao mesmo tempo.

Baker \& Hacker, RGN, p. 180.

Cf. ibidem, p. 166 e ss. 